\title{
The globalization of international oilseeds trade
}

\author{
Jean-François MITTAINE ${ }^{1}$ \\ Thomas MIELKE ${ }^{2}$ \\ 1 Oil World, \\ Fish, Oil \& Meal World (France), \\ Fishmeal Experts, \\ 2 Rue des Bois, \\ 92410, Ville d'Avray, \\ France \\ $<$ jean-francois. \\ mittaine@fishmealexperts.com> \\ 2 Oil World and Fish, \\ Oil \& Meal World (Germany), \\ ISTA Mielke $\mathrm{GmbH}$, \\ Langenberg 25, \\ 21077 Hamburg, \\ Germany
}

Article received 12 July 2012

Accepted 30 July 2012

\begin{abstract}
In a globalised world, the trade of goods and services constitute the heart of the economic system. But the trade patterns may show extreme diversity depending upon the nature of the concerned products. The technical and functional constraints do impose their laws, particularly when they relate to biological products/commodities. The term globalization is generally used to describe a complex process of international integration. When referring to oilseeds, the term must also relate to agriculture and human nutritional requirements for a rising human population spread all over the world, particularly in large urban environment.

With an annual harvest of about $450 \mathrm{Mn} \mathrm{T}$, oilseeds are naturally "globalized" in their production patterns. The complexity of their production schemes associated with the diversity of their usage on widespread geographical regions gives this group of commodities a unique role on the world markets. This process of opened trade channels has enabled the sector to meet the supply requirements of a quickly rising demand coming from both the population and all the industrial usages including alternative "green" energy.

However, for the time being, demand growth has not been fully counter-balanced by production growth. As a consequence, unless some strict reallocation of acreage is effectively organized or new high yielding technologies are developed, it is a fact that vegetable oil will keep a strong demand base for a long time, compounded by the mechanical demand from economic growth in highly populated emerging economies. The balancing of supply and demand is expected to remain a tight exercise every year. At the end of the day, the future of the entire industry largely lies in technology because the final stake is to ensure the proper feeding of a 9 billion people population in a not too far future.
\end{abstract}

Key words: Oilseeds, oil meals, vegetable oil, commodity markets, globalization, GMO seeds, biodiesel

considered to be most reliable and they are carefully controlled. They are regularly updated. The utilization of these data outside this paper is only possible after authorization and eventually updated by the authors.

\section{Data:}

All data presented in this paper are coming from the database of ISTA Mielke $\mathrm{GmbH}$, Hamburg, Germany, the publisher of "Oil World" who have been compiling them and many others for over 50 years. They have been collected from sources
In a globalised world, the trade of goods and services constitute the heart of the economic system. But the trade patterns may show extreme diversity depending upon the nature of the concerned products. The technical and functional constraints do impose their laws, par- ticularly when they relate to biological products/commodities.

Therefore, it is not surprising that in a system as complex as the oilseeds one (seeds, oils and meals), it is rather difficult to synthesize in only few pages what the "globalization of oilseeds trade" is all about. However, it is this kind of exercise to which we'll submit in a very simplified manner by focusing on the major relationships and market fundamentals and drawing some indicative perspectives enabling us to provide some tracks towards a certain vision of the future.

To cite this article: Mittaine JF, Mielke T. The globalization of international oilseeds trade. OCL 2012; 19(5): 249-260. doi : 10.1684/ ocl.2012.0470 


\section{What does \\ "Globalization" mean in the context of the oilseeds complex?}

The term globalization is generally used to describe a complex process of international integration. Of course, when referring to farm commodities and basic food items, the term must also relate to agriculture and human nutritional requirements for a rising human population spread all over the world, particularly in large urban environment. Although agriculture in itself is not naturally a "globalized" activity as it is directly related to land i.e. sedentary, the trade of farm products has been at the heart of international trade in the past centuries for the simple reason that farm production surpluses were increasingly located away from the deficit regions. Except for vegetable oil (remember the olive oil trade in the Mediterranean basin in the Roman Empire), the international trade of oilseeds and products was traditionally less important than that of grain or even tropical products (sugar, coffee, cocoa, etc.). At the end of World War II, as world trade of goods grew very fast thanks to sharply reduced trade barriers, farm products continued to constitute an exception in all the GATT (General Agreement on Tariffs and Trade) trade negotiations. In spite of their importance, the share of farm products in total world trade of goods consequently declined very regularly in the past decades from $14.7 \%$ of total merchandise trade in 1980 to $8.9 \%$ in 2010.

The oilseeds sector may be an exception in this decline. This is because oilseeds and their products are naturally "globalized" in their production patterns: not only can they be found in both tropical and temperate climates but also in both the north and south hemispheres. The key crushing activity, the first industrial step of the valuechain, is not only located near the production zones (the USA and Brazil) but also close to the consumption zones (China). Oilseeds and their products are of great importance in the advanced economies where per capita consumption is high but also in emerging markets where population is large and where per capita consumption of vegetable oils and livestock products has

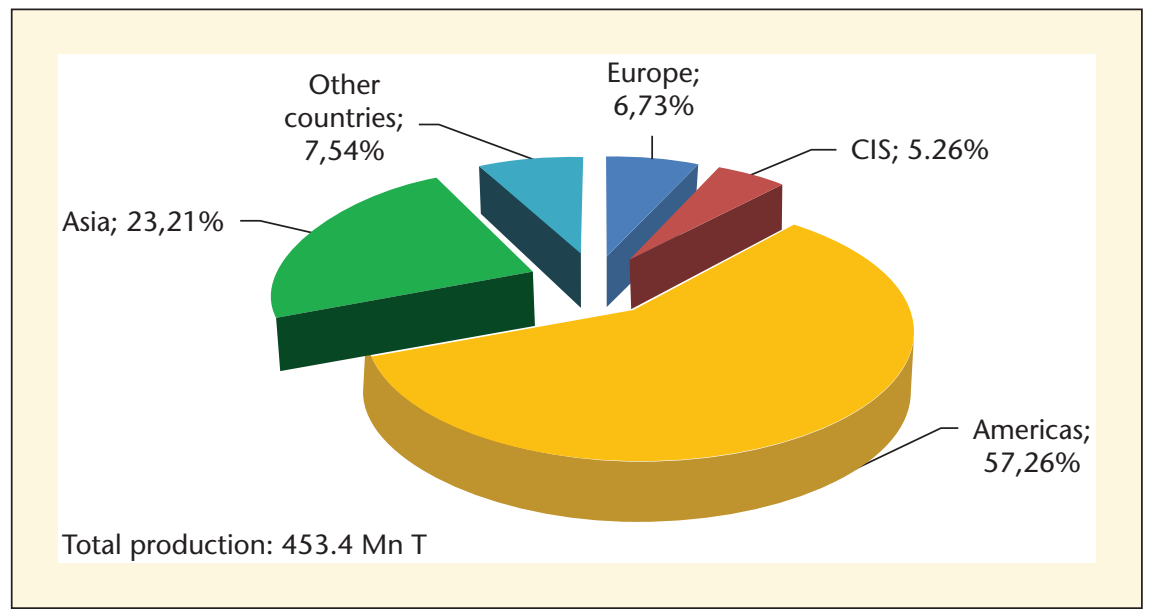

Figure 1. World production of oilseeds by main regions (Year 2011). accelerated in the past 15 years together with rapidly rising disposable income primarily in China and India, which together represent $40 \%$ of the world population. Oilseeds products from the crushing industry are used not only as food but also as key ingredients in some strategic industries (chemistry), including providers of energy (biodiesel). Finally, they are used as food for direct human consumption as well as feed in all modern animal production industries.

The complexity of their production schemes associated with the diversity of their usage on widespread geographical regions gives this group of commodities a unique role on the world markets.

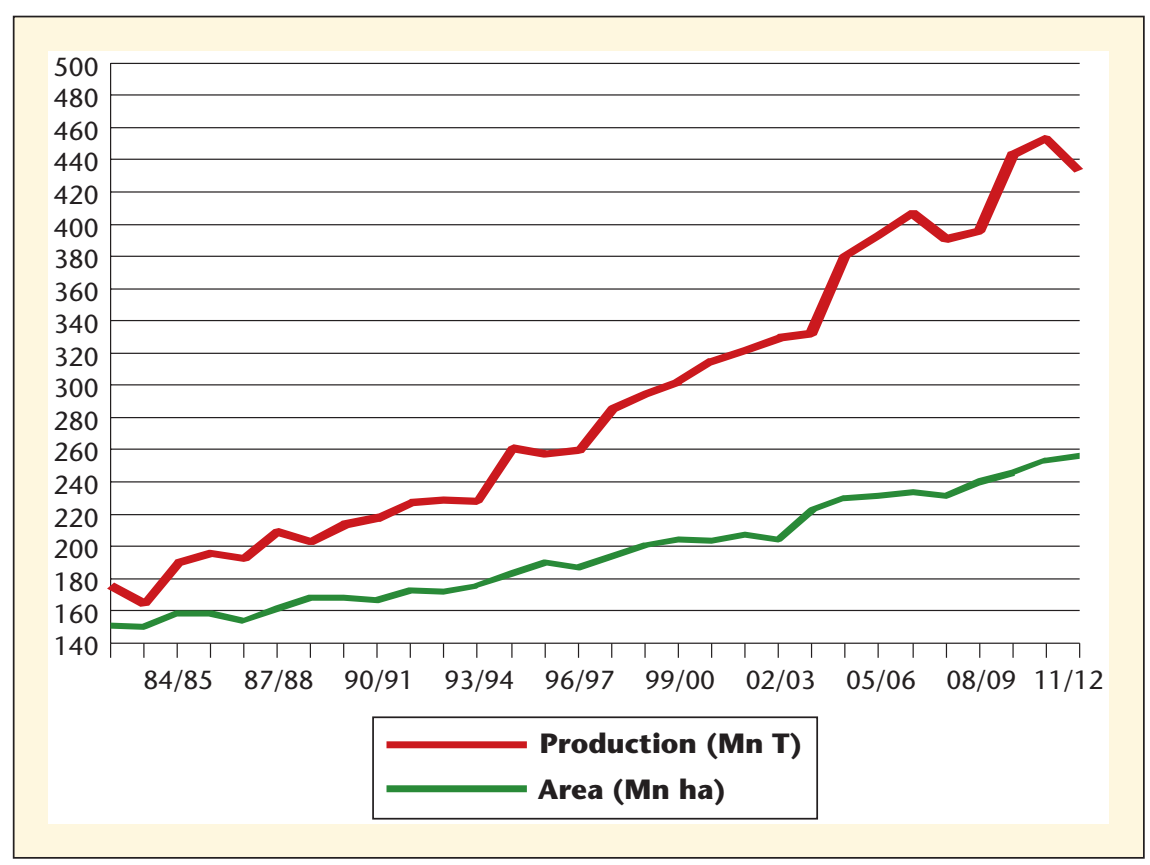

Figure 2. World area and production of the major 10 oilseeds (soybeans, cotton seed, rapeseed, sunflower seed, groundnuts (shelled), sesame seed, palmkernels, copra, linseed and castor seed). 


\section{A "globalized" production?}

With an annual harvest exceeding 450 million tons, oilseeds production is only $20 \%$ the size of the world grain production (all grains). Just like grains, oilseeds are harvested in all continents of the world, under all sorts of climates, in both northern and southern hemispheres, from a variety of plants of totally different origins. However, more than $57 \%$ of all oilseeds originate on the American continent (figure 1) on account of the dominance of soybeans in the complex. With $23 \%$ of the harvested production, Asia is the second largest source of oilseeds due to the importance of China and India, where about 19\% of world oilseeds harvest is located. Europe and the CIS which constitute a traditional source of "high oil yielding" oilseeds (rape and sunflower) together originate only $12 \%$ of world harvests.

Oilseeds production growth all over the world has been remarkable in the past 25 years (figure 2). Indeed, world production of the major 10 oilseeds (soybeans, cotton seed, rapeseed, sunflower seed, groundnuts -shelled-, sesame seed, palmkernels, copra, linseed and castor seed) rose from about $190 \mathrm{Mn} \mathrm{T}$ in $1985 / 1986$ to more than $453 \mathrm{Mn}$ T in 2010/2011, a 136\% rise in a quarter of a century representing an average of $5.5 \%$ per year. Quite an impressive number when compared with, for example, the "grains" sector (wheat, coarse grains and rice) which experienced a $34 \%$ production growth in the same period, from $1647 \mathrm{Mn} \mathrm{T}$ in 1985 to $2213 \mathrm{Mn}$ T in 2010. This is only roughly $1.3 \%$ annual increase.

Acreage planted in all oilseeds rose from $160 \mathrm{Mn} \mathrm{Ha}$ to $260 \mathrm{Mn} \mathrm{Ha}$, a $62 \%$ rise during the same period. This means that the productivity gains for oilseeds have been quite remarkable, rising from an average of $1.18 \mathrm{~T} / \mathrm{Ha}$ in $1985 / 1986$ to $1.73 \mathrm{~T} / \mathrm{Ha}$ in $2010 / 2011$, a $47 \%$ increase, i.e. roughly $1.9 \%$ productivity gain per year... on average for the entire world! This was, however, not purely linked to yield improvements but also to a shift in acreage from lower yielding to higher yielding regions and it also reflected stronger growth of production of higher yielding oilseeds. These two factors contributed to this increase in the world average yield.

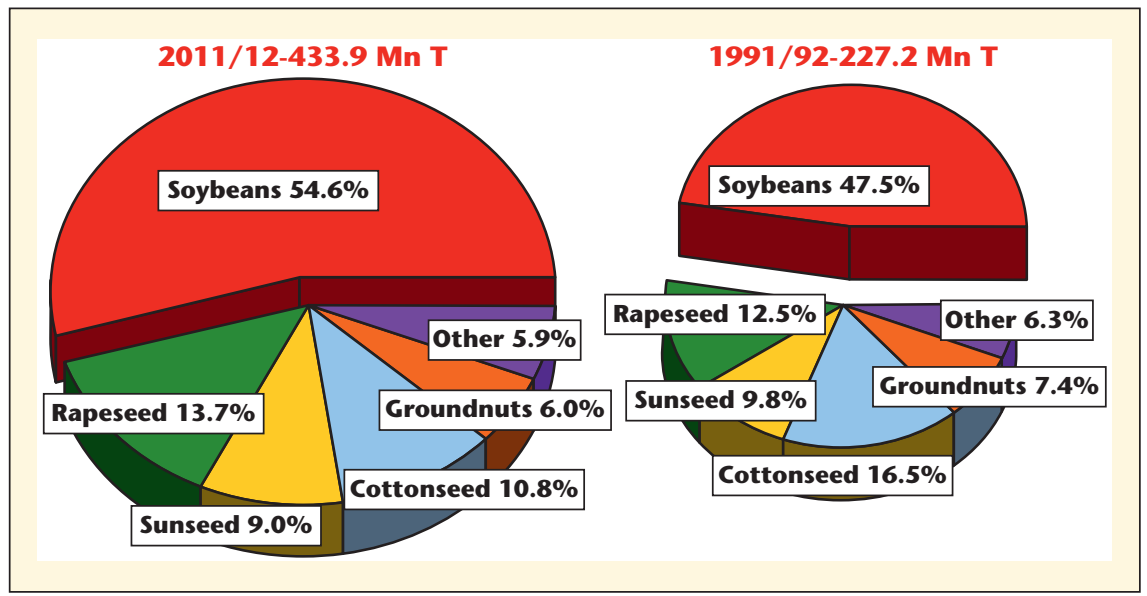

Figure 3. World production (year 2011/12 vs 1991/92) of 10 oilseeds (soybeans, cotton seed, rapeseed, sunflower seed, groundnuts (shelled), sesame seed, palmkernels, copra, linseed and castor seed).
The analysis of the world production by become dominant in this sector. Although in 1991/1992, soybeans represented only $47.5 \%$ of all oilseeds produced in the world, a "mere" 107.92 Mn T, ten years later soybeans represent $54.6 \%$ of all oilseeds produced, i.e. $236.9 \mathrm{Mn} \mathrm{T}$, a rise of roughly $120 \mathrm{Mn}$ T (figure 3).

The other major oilseeds do naturally represent the more "traditional" oilseeds as we know them in Europe in type of seed shows how soybeans have temperate climates: rapeseed and sunflower seed, two high oil yielding seeds (around $45 \%$ oil vs only $18 \%$ for soybeans), represent only $22.7 \%$ of world production in 2011/2012 (13.7\% for rape and $9.0 \%$ for sunflower), i.e. a total of $98.4 \mathrm{Mn} \mathrm{T}$. This compares with a combined $22.3 \%$ share of world production in 1991/1992, i.e. about $51 \mathrm{Mn} \mathrm{T}$. Consequently, world production of these two key oilseeds rose by only $9 \%$ in the last 10 years. In spite of a significant production rise of $41.3 \%$ or $1.6 \%$ per annum in the last

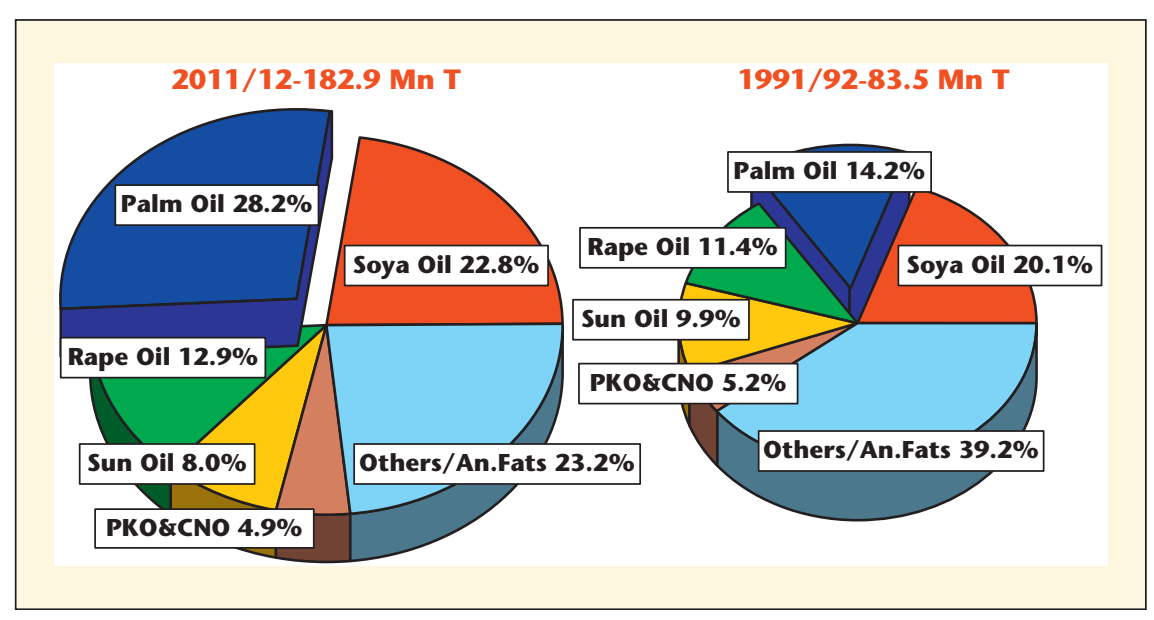

Figure 4. World production (year 2011/12 vs 1991/92) of 17 oils and fats: soya oil, palm oil, rapeseed oil, sunflower oil, cotton oil, groundnut oil, sesame oil, corn oil, olive oil, palmkernel oil, coconut oil, butter as fat, lard, fish oil, linseed oil, castor oil, tallow \& grease. 
10 years, the share of tropical oilseeds like cotton and groundnuts and "other" oilseeds declined sharply in the world production from $30.2 \%$ of the total (69.7 Mn T) downto 22.7\%(98.5 Mn T).

World production of the 17 oils and fats (soya oil, palm oil, rapeseed oil, sunflower oil, cotton oil, groundnut oil, sesame oil, corn oil, olive oil, palmkernel oil, coconut oil, butter as fat, lard, fish oil, linseed oil, castor oil, tallow \& grease) will reach $182.9 \mathrm{Mn} \mathrm{T}$ in 2011/2012 (October/September) a sharp 119\% over the corresponding period 20 years ago (83.5 Mn T, see figure 4), roughly a $5.5 \%$ growth per annum. Quite an impressive growth but also quite welcome when compared with world demand, as we'll analyze later.

While ranking second in this group of oils and fats in 1991/1992, palm oil has become the largest vegetable/ animal oil produced in the world, expected to reach 51.5 Mn T in 2011/ 2012, compared with only $11.9 \mathrm{Mn} \mathrm{T}$ in $1991 / 1992$, a remarkable $330 \%$ rise in 20 years corresponding to approximately $16.6 \%$ per annum. More remarkable is that $85 \%$ of this world production comes from only two countries, Indonesia (25.2 Mn T) and Malaysia (18.6 Mn T), far above the third largest production in Thailand (1.62 Mn T).

With 41.7 Mn T, soya oil is the second largest vegetable oil produced in the world and also experienced a sharp $148 \%$ rise in production in the last 20 years, corresponding to an astounding $7 \%$ per year. Rape and sun oils combined today represent about $21 \%$ of world production about unchanged from 20 years ago in terms of production share but still rising from 17.8 Mn T to $38.2 \mathrm{MnT}$, more than a twofold increase. Finally all the other oils including animal fats are declining in importance from $39.2 \%$ to $23.2 \%$ of the total during the period, although this decline in production share still represents a $10 \mathrm{Mn} \mathrm{T}$ rise in total production from 32.7 Mn T to 42.4 Mnt. Let's not forget though that in addition to those 17 oils \& fats which we are considering in the "Oil World" database, there are many additional vegetable oils of all types but generally found in small volumes, particularly from tropical sources that are used by various industries, particularly the dynamic cosmetic industry. These "exotic" oils still represent very small

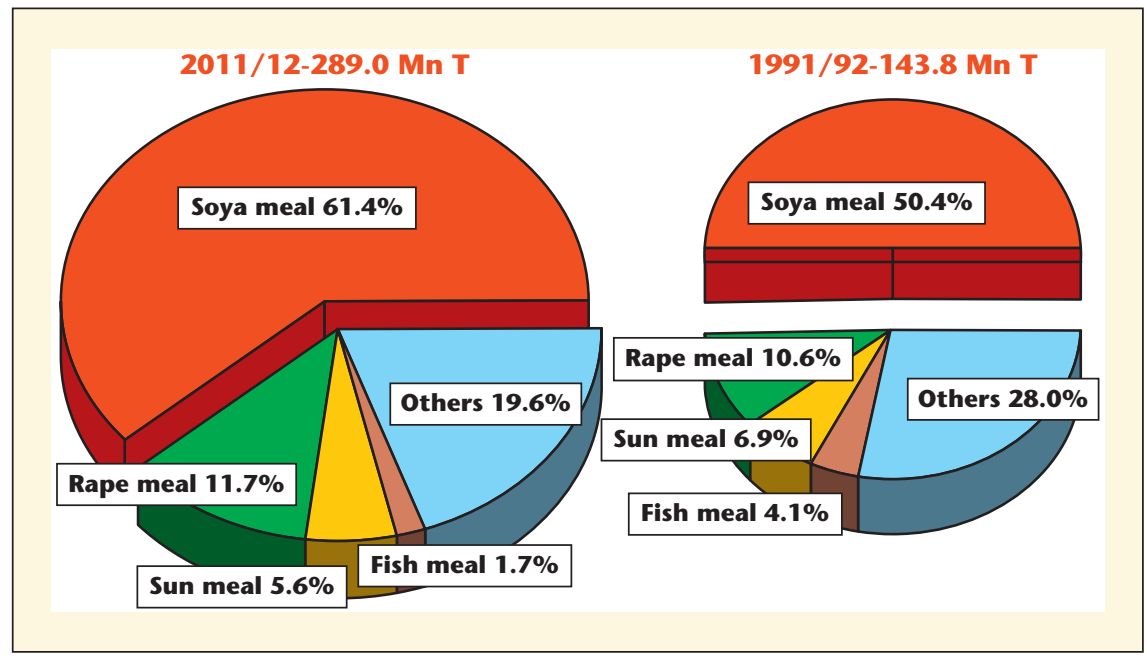

Figure 5. World production (year 2011/12 vs 1991/92) of 12 oils meals: soya meal, rapeseed meal, sunflower meal, cottonseed meal, groundnut meal, sesame meal, corngerm meal, cornglutenfeed, palmkernel meal, copra meal, linseed meal, fish meal. tonnages compared with the other bigger productions but offer many "globalization" opportunities, all the more that they are directly associated with a very high technology.

World production of the 12 oilmeals (soya meal, rapeseed meal, sunflower meal, cottonseed meal, groundnut meal, sesame meal, corngerm meal, cornglutenfeed, palmkernel meal, copra meal, linseed meal, fish meal) is expected to reach $289.0 \mathrm{Mn} \mathrm{T}$ in $2011 / 2012$, just a twofold rise from 20 years ago (143.8 Mn T in 1991/1992, see figure 5), the lowest rise of the three

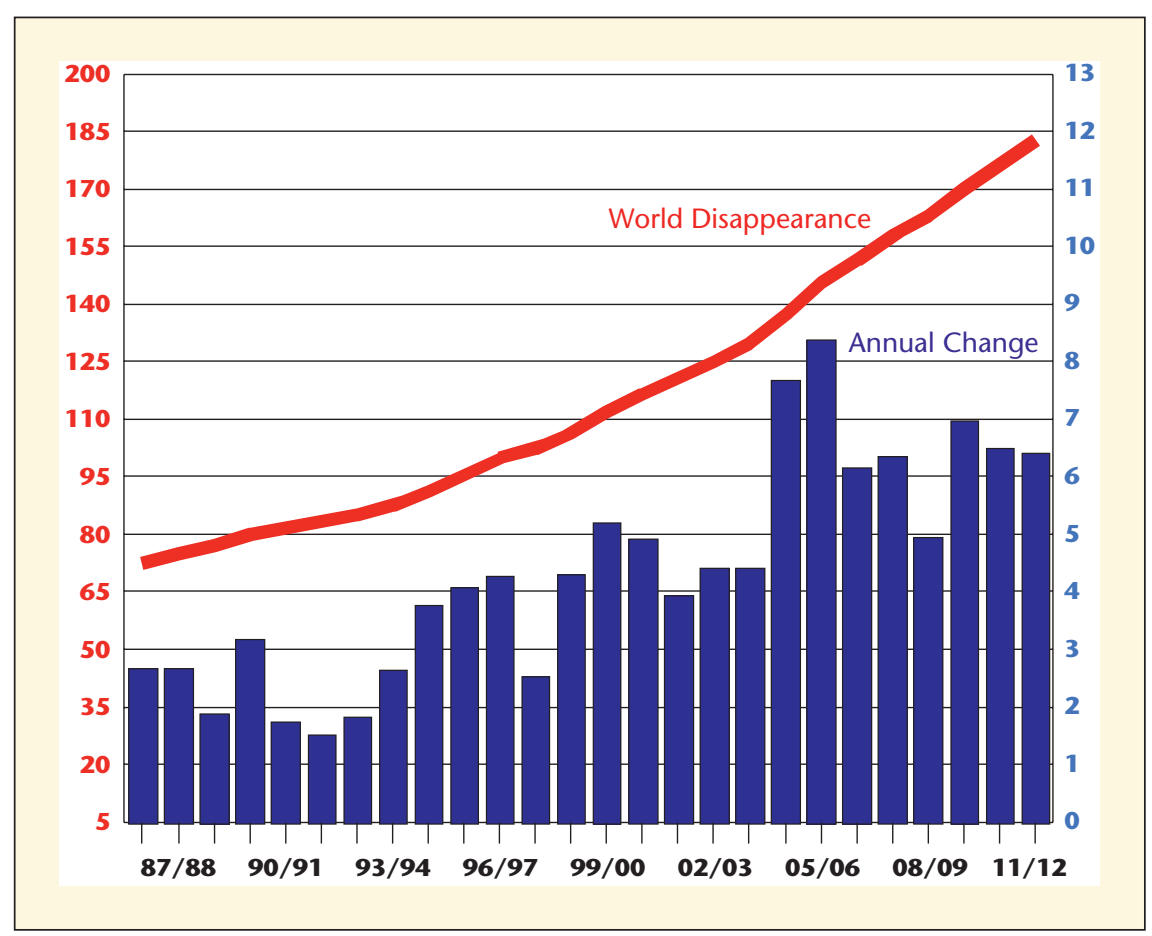

Figure 6. Total usage ans annual Change (Mt) of 17 oils and fats since 1987/88. 
key sectors discussed in this review. As expected from the above, soybean meal is, by far the largest component of this group representing now more than $60 \%$ of the world total, up from just over $50 \%$ twenty years ago. But, when expressed in tons, this increase in world market share represents a production rise of about $105 \mathrm{Mn} \mathrm{T}$ ! As a consequence, soybean meal has taken over from the "other" meals the share of which dropped from $28 \%$ of world production to less than $20 \%$ and also fishmeal. The combined share of rape and sun meals remained stable around $17.3 \%$ actually not far below the share of their respective oils, but still an impressive twofold growth in tonnage from 25.2 Mn T to 50.0 Mn T.

\section{A "globalized" consumption?}

Being a key food staple, it is only natural that oilseeds products be globalized in their consumption patterns. Actually, this demand side of the analysis must draw a line between the oils and the meals since the latter is essentially utilized as feed, therefore entering into a whole new value-chain, i.e. animal production.

Firstly, total world usage of the 17 fats and oils have shown a rapidly growing tendency in the past quarter century (figure 6), reaching around $185 \mathrm{Mn} \mathrm{T}$ in $2011 / 2012$ from a starting point below $80 \mathrm{Mn} \mathrm{T}$ in $1987 / 1988$. It is important to realize how remarkable it is that the world farming system been able to make available on the global markets more than $100 \mathrm{Mn} \mathrm{T}$ additional production in such short period (at least compared with the centuries of our agricultural development). However, the point is that, although the annual growth rate of total usage seems to be more or less stabilizing, this rate still remained around $6 \%$ to $7 \%$ per year in the past eight years. This particularly high rate of growth can for example be compared with the average world GDP growth rate of the past years of only $4 \%$ to $6 \%$ per year (figure 7). This preoccupation of the quickly rising usage of the 17 fats and oils must also be related to the balance between world output and consumption of the 10 key oilseeds (figure 8)

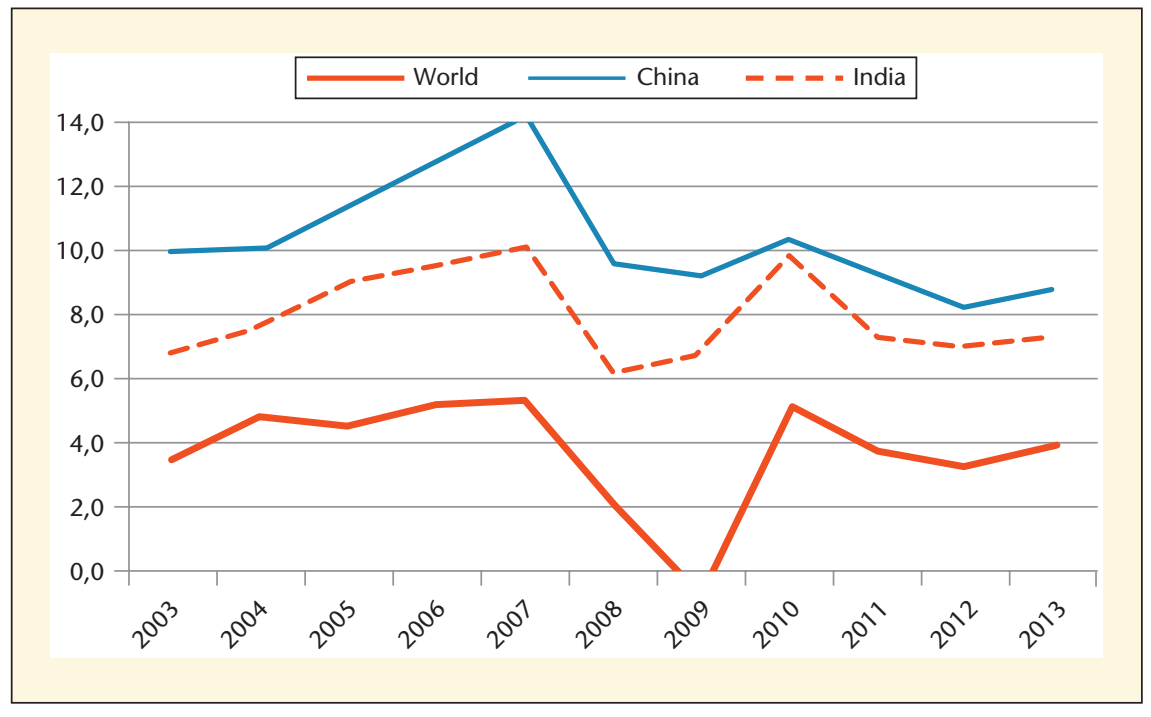

Figure 7. World and selected countries (China, India) gross domestic product (GDP) growth, in $\%$ annual change.

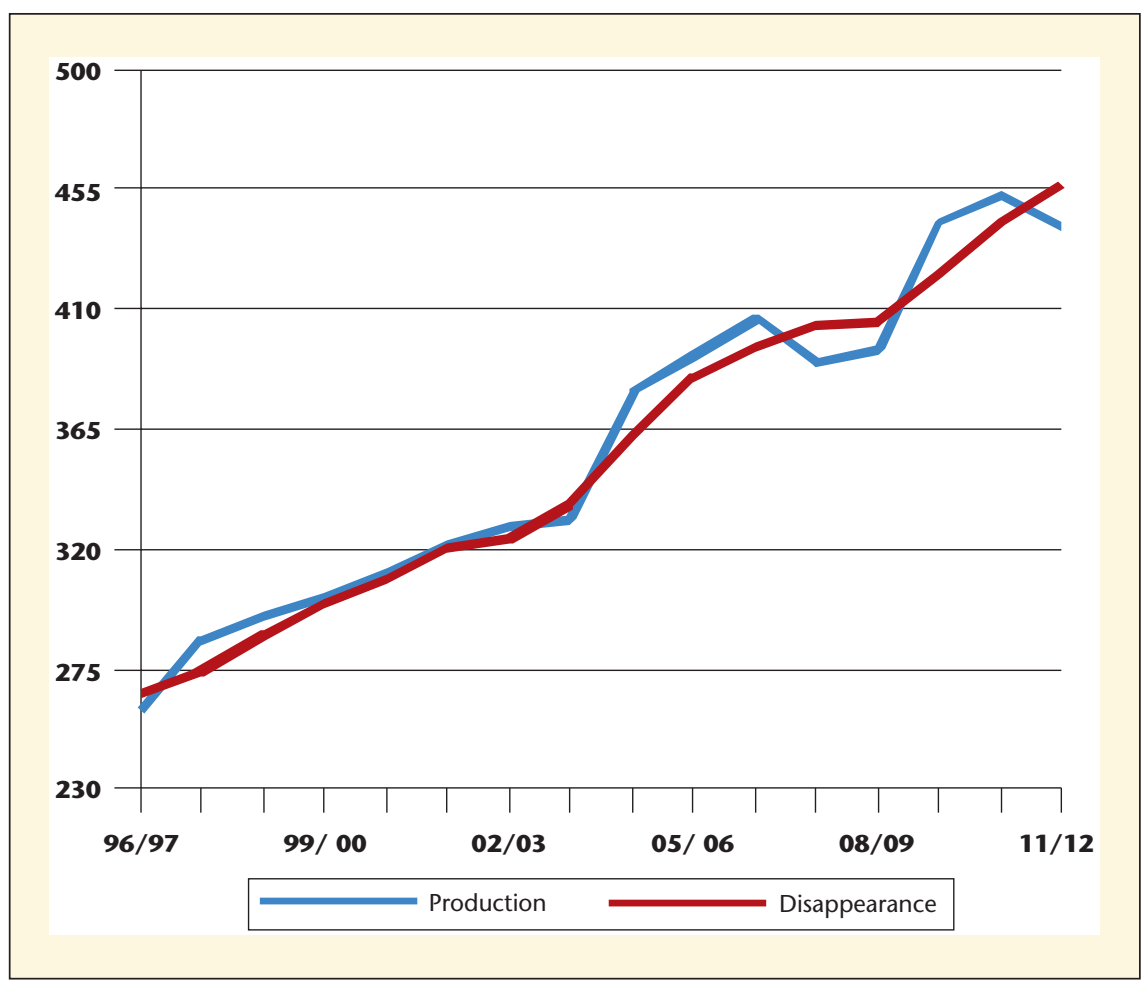

Figure 8. World output and consumption of 10 oilseeds (Mn T). 
which shows that the likelihood of a production shortage is not totally unrealistic. This is probably one reason why the markets are extremely sensitive to any production shortfall as witnessed few months ago in South America and feared in the USA in the coming months.

World consumption of oils and fats is well balanced geographically according to population and disposable income as illustrated in figure 9 which relates only to the 13 vegetable oils for the period $1996 / 1997$ and $2011 / 2012$. Aside from the overall world consumption growth of about $99 \%$ over the period, the share of the various geographical regions has remained rather stable with the major exception of China, the share of which is logically rising. This is associated with the evolution of per capita consumption of fats and oils in the world (figures 10 and 11).

Since 1996, per capita world consumption of 17 oils and fats has increased from $16.86 \mathrm{~kg}$ in 1996 to $25.56 \mathrm{~kg}$ in 2011, up 51\%, corresponding to an average yearly growth of around 3\% per year. Figure 10 shows how a selected group of countries is faring in 2011: Argentina, the EU-27 and the USA remain the highest per capita consuming regions in the world, at about twice the world average. But, part of this is due to the large consumption of oils and fats as a feedstock for biodiesel. In spite of a huge rise of per capita consumption since 1996 (respectively $+121 \%$ and $+57 \%$ ), the two large emerging countries, China and India, still remain below the world average at respectively $24.6 \mathrm{~kg}$ and $14.6 \mathrm{~kg}$ per capita. It is known however that they will most likely exceed the world average quite rapidly as a result of their quickly rising disposable income.

In the 15 years' period of 1996 to 2011, world meal consumption rose from 169.4 Mn T to 283.5 Mn T, a comparatively low $67 \%$ compared with the oil sector (figure 12). This is mainly due to the fact that the oil sector benefited from large palm oil supplies which practically do not generate any meal. Of course, this is partly counterbalanced by the large soya meal consumption which, at $174.9 \mathrm{Mn} \mathrm{T}$ in 2011 , represents about $62 \%$ of total world consumption, growing at a rate of $49 \%$ in the 15 year's period, an average of about $3 \%$ per year.

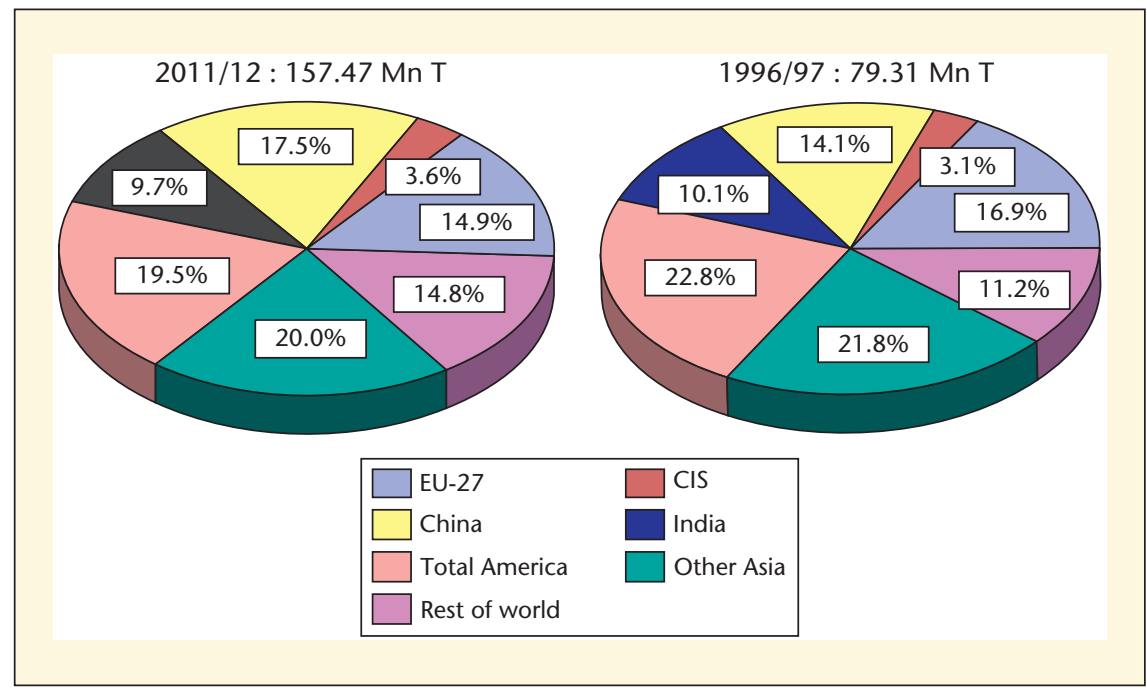

Figure 9. Consumption (year 2011/12 vs 1996/97) of 13 Vegetable oils by major countries (MnT).

in $\mathrm{kg} /$ year/person

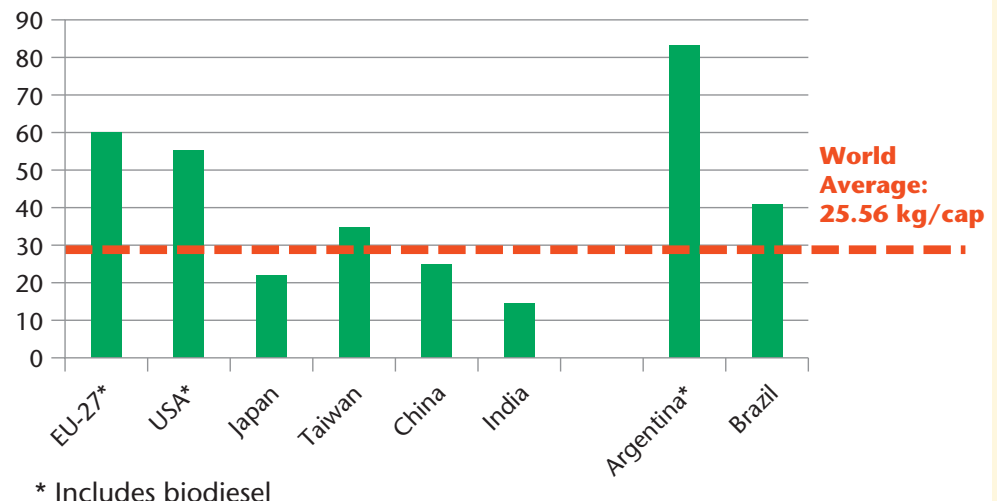

* Includes biodiesel

Figure 10. Per capita consumption in year 2011 of 17 fats ans oils of selected countries, compared with world average.

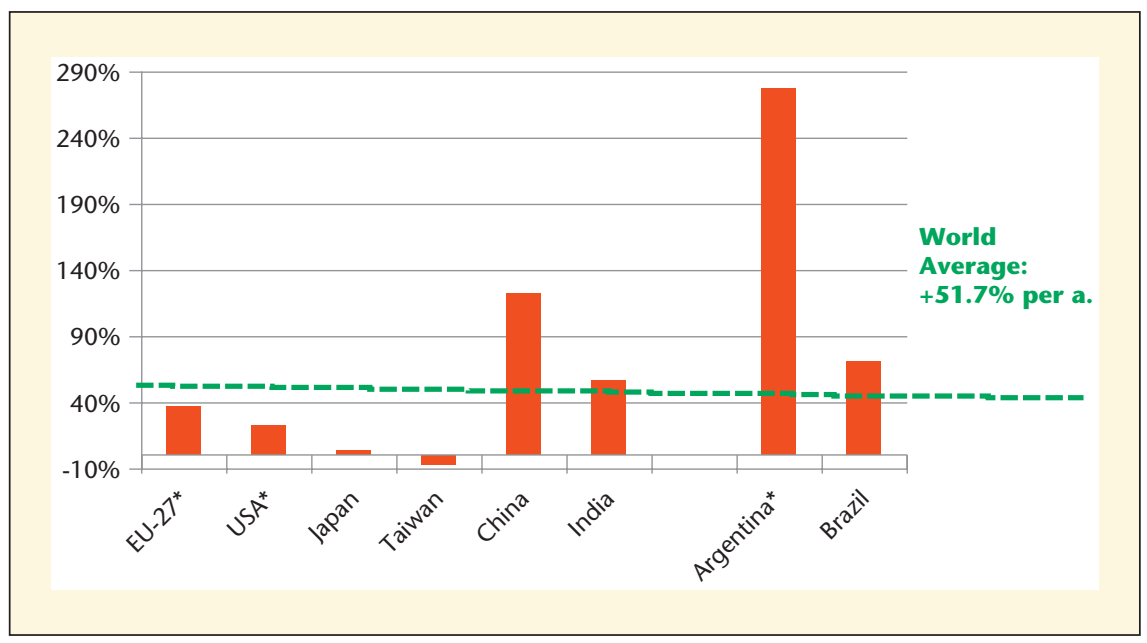

Figure 11. Change 2011 vs 1996 in per capita consumption in year 2011 of 17 fats ans oils of selected countries, compared with world average. 


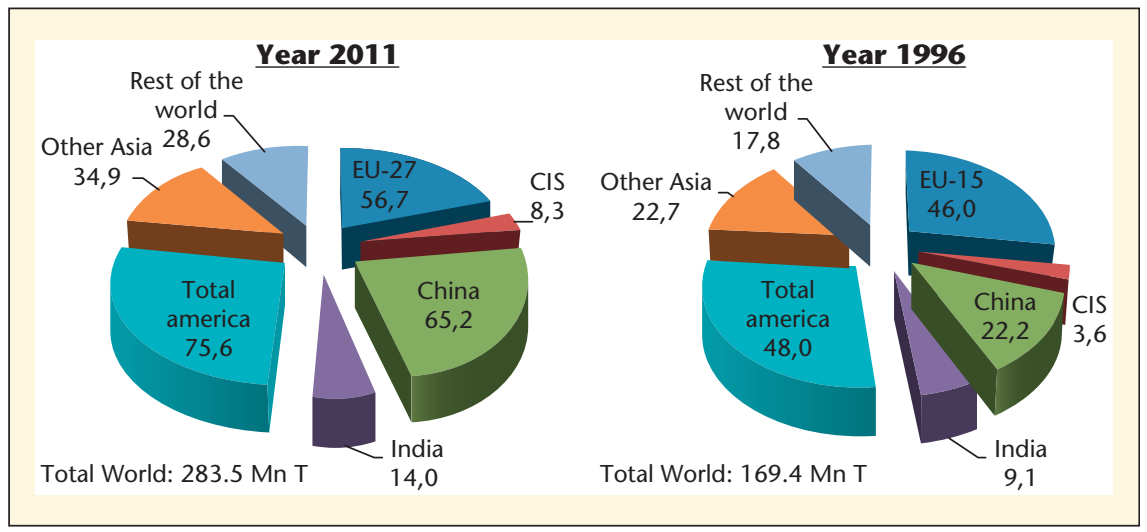

Figure 12. Consumption by major countries (in Mn T) of 12 oil meals, in year 2011 and 1996.

\section{The main flows in the world trade of oilseeds and products}

World trade of oilseeds and their products (oils and meals, only of vegetable origin) represented a total of about 254 million tons in 2011. In other terms, world exports of these three groups of commodities represent about $28 \%$ of world production. For a basic "food" group of commodities, this ratio is relatively high, much higher than most, if not all, grains. This means that for many key producing and consuming countries, reliance on international trade flows is high. The reasons are numerous, among them a significant geographical concentration of productions in the Americas, on account of the growing role of soybeans in the whole complex combined with rising deficit countries with large populations the wealth of which is growing quickly.

This is clearly the case in China where the domestic production deficit has widened at an alarming rate, substantially raising import requirements of oilseeds, oils \& fats and oil meals and most recently also of grains - due to the rapidly increasing domestic consumption and insufficient production. The arable agricultural land in China has been shrinking over the past several years, partly as a result of wind erosion and degradation of land and partly in response to increased requirements of the growing population (for infra-structure, housing, etc.). Also, it is difficult in China to increase yields of oilseeds and
91\% of these exports were constituted of five farm products: soybean, rapeseed, sunflower seed, cotton seed and palm oil.

In the oil sector, the role of palm oil has been instrumental in enabling a relative balancing of supply and demand worldwide as illustrated in figure 14. Actually, world exports of vegetable oils have been dominated by palm oil and, to a lesser extent by the soybean/rapeseed/ sunflower oils. But the bulk of the world supply of vegetable oils through world trade has been carried by palm oil the trade of which has experienced a twofold production increase and a near triple rise of exports in 15 years (figure 15).

\section{Some other key aspects of the world trade of oilseeds.}

During the past 20 years domestic consumption of 17 oils \& fats almost quadrupled in China while domestic usage of 12 oil meals almost quintupled. China became the world's largest importer of soybeans - currently accounting for about $62 \%$ of world imports while the country was a net exporter of soybeans 20 years ago.

The share of each subgroup in world exports is also significant of the way globalization works in this sector. It is indeed no surprise to note that generally oilseeds have been the dominant group of commodities entering world trade channels (43\% in 2011 - figure 13) followed by meals (31\%) and significantly behind vegetable oils (26\%). And

(1) The key role of the American continent, particularly three countries, the USA, Argentina and Brazil, in the supply of soybean, the dominant oilseed on the world markets, is probably the most important characteristic in this world trade of oilseeds. Their situation in both northern and southern hemisphere allows a unique market function through two harvests for every annual production cycles. Every year, the "North/South" balancing effect in the trading activity provides a unique character in the entire world commodity trade.

(2) Also, both North and South Americas are exposed to the developments of the generally very small sizes of farms)

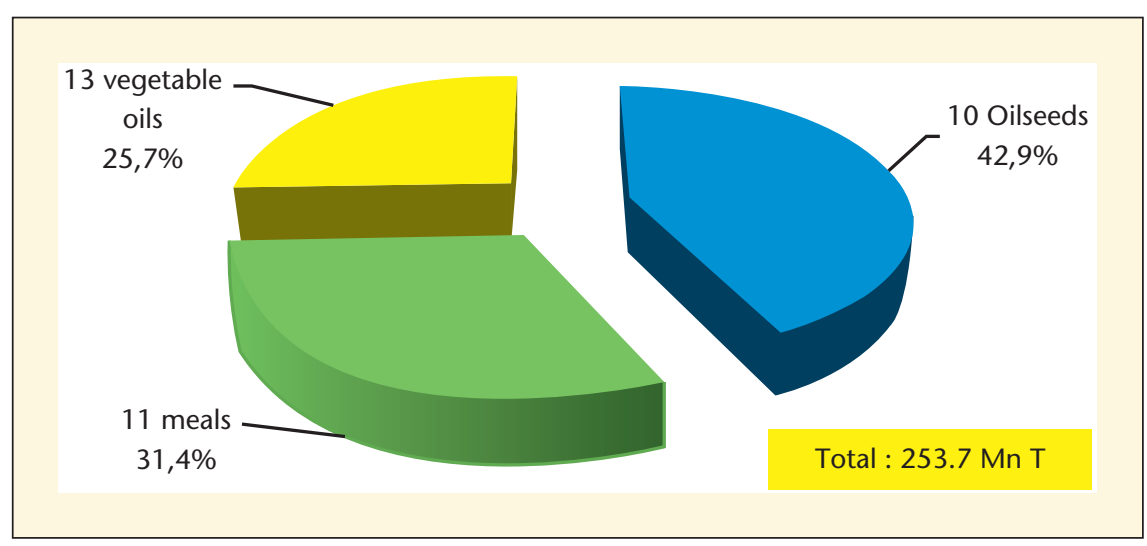

Figure 13. Share of oilseeds and products in total world exports in 2011 (in \%). All non vegetable oils and meals are excluded. 


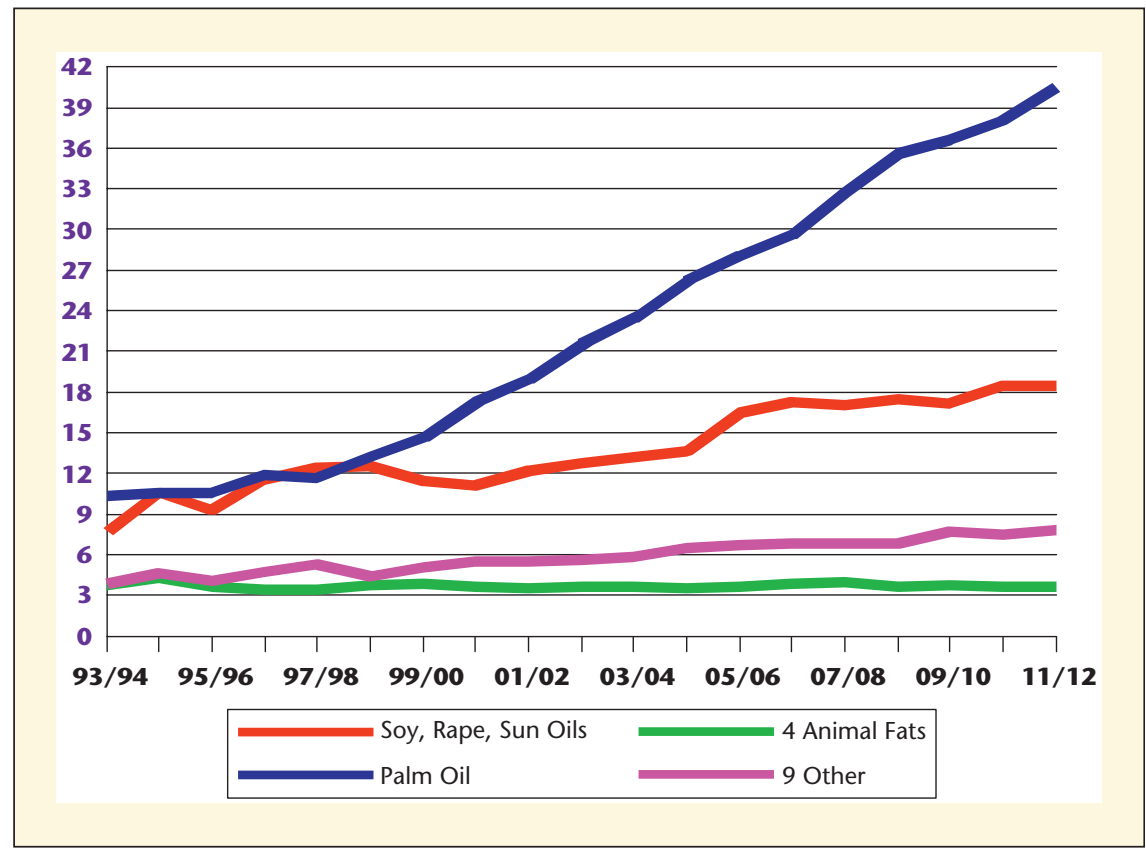

Figure 14. World export of 17 oils and fats (in Mn T).

"El-Niño"/"La-Niña" (warm event/cold event) in the Pacific Ocean with the resulting drought/rains alternatively in the Great Plains of the USA or in Brazil/ Argentina. As a result, the entire oilseeds complex is probably the most exposed to this very important climate cycle. case of problems (climate, political or other), in those two countries geographically very close to each other. In addition, the life cycle of this production is completely different from all other sources of vegetable oil. Palm tree plantations are operating on multi-year basis and the massive renewal of the plantations is an experience that the world markets have not experienced yet but which will be causing some complex problems of production management in a not too far future.

(4) Aside from cotton and corn, the growth of genetically modified organisms (GMO) in the oilseeds sector is probably one of the key far-reaching developments in the entire commodity environment. World plantings of GMO crops are rising rapidly (figure 16) now reaching more than $160 \mathrm{Mn}$ hectares, all of this growth occurring in the past 15 years. Because of the rising role of $\mathrm{GMO}$ in the soybeans and corn sectors, it is no surprise to note that more than three quarters of GMO crops are raised in three countries of the Americas (figure 17): the USA (43.1\%), Brazil (18.8\%) and Argentina (14.8\%). The non-acceptance of GMO commodities by some consuming regions generates significant new trade patterns but also significant potential problems in terms of the smooth balancing of world supply/demand.

(5) Finally, the quick growth of biodiesel usage for some important vegetable oils, like rape oil for example, constitute another key aspect of this market. World production of biodiesel has been rising extremely rapidly from around $2 \mathrm{Mn} \mathrm{T}$ in 2003 to more than $23 \mathrm{Mn} \mathrm{T}$ expected in 2012 (figure 18). This is a tenfold rise in 10 years! As a consequence, the share of biodiesel in world fats and oils consumption has become important (figure 19). About half of the world biodiesel production is found in two regions: first and foremost, the EU27 (with an annual production of 9.0 Mn T per year) of which Germany and France constitute the largest producers and the USA (about 2.8 Mn T per year) (figure 20). Of course, the development of this alternative energy is directly influenced by the price of petroleum. But its growth is raising questions in terms of competition for acreage in some regions of the globe. There are numerous questions being raised as to the real logic of such

Figure 15. Growth of production and exports (2011 vs 1996) of 17 oils and fats and selected oils. 


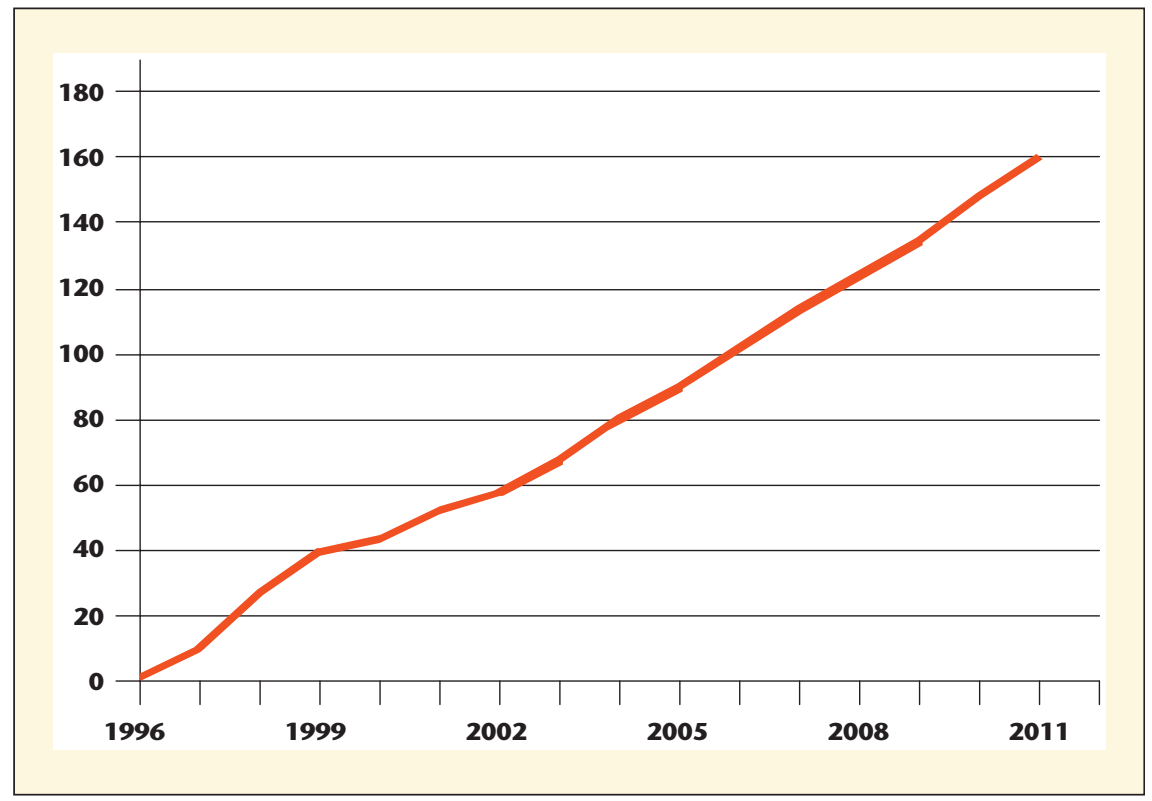

Figure 16. World area of genetically modified crops (Mh ha).

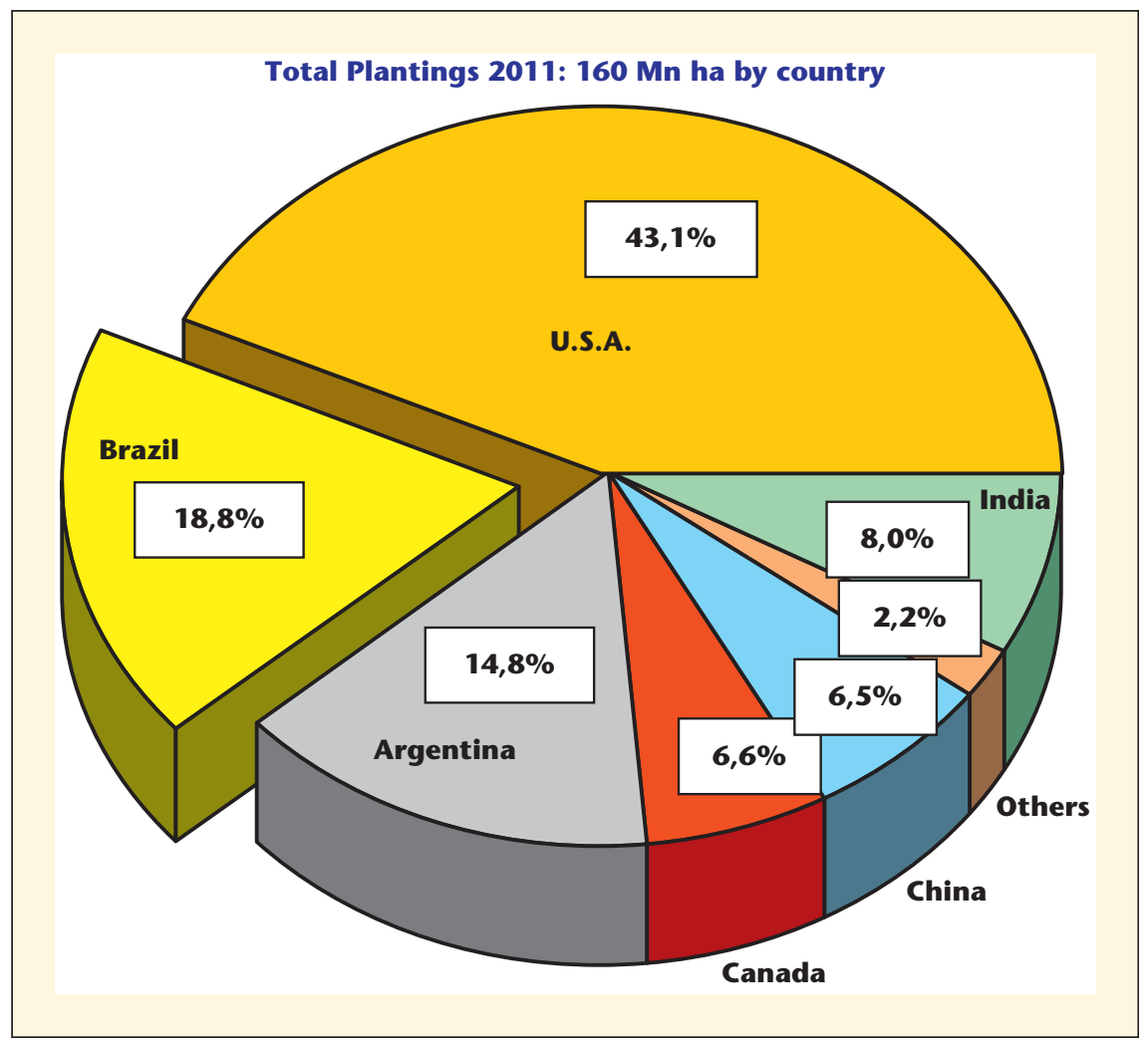

Figure 17. World planting of genetically modified crops. biodiesel usage while the food usage of vegetable oils is in such tight supply/ demand balance with all the risks that could develop in case of a real shortage of vegetable oils caused by sharp production shortfalls.

\section{The markets}

Like any other commodities, the oilseeds markets have been faced by rising prices in the past decade combined with high volatility (figure 21) on account of:

(1) The generally tight supply/demand situation where any minor change in the anticipations of the operators generates a quick and sometimes brutal and irrational reaction on prices. This is particularly the case when unexpectedly unfavorable climate conditions reduce crop sizes sharply in one of the key producing countries. This situation has been particularly well illustrated in 2011/2012 when the drought in Argentina has considerably reduced the soybean crop followed by the current scare on North American soybeans. The additional role of "El-Niño" on North and South American climate conditions is an important market factor affecting both the level of prices and the volatility.

(2) Technical progress in this sector of oilseeds/fats \& oils has been such that consumption is far more price elastic than few years ago. The consequence is that oils and fats prices are now closely correlated.

(3) Most markets of this group of commodities are extremely transparent notably on account of the role played by the futures markets and other derivative market in the pricing process. Aside from the traditional "hedgers", the rising presence of large speculators, some of them operating under the "high frequency" type of trade, has sharply raised market volatility.

(4) Consumers have become more and more flexible in terms of their purchasing requirements. They react more quickly than before to both fundamental supply/demand imbalances and technical price variations. Substitution has become far more common particularly in all sectors associated with feed formulation.

(5) The rising technology involved in oil usages combined with their specific technical requirements have led to much segmentation of the oil markets 


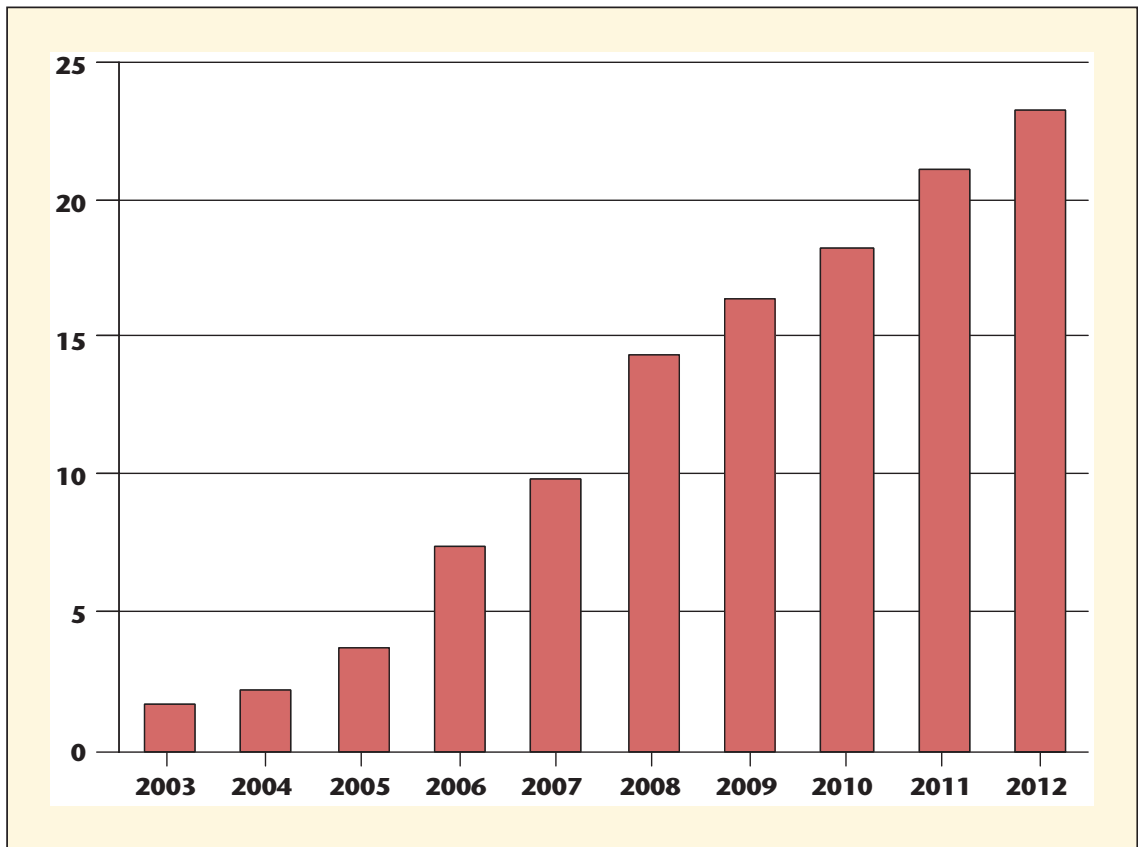

Figure 18. World production of Biodiesel (Mn T).

with wide variety of prices according to the level of sophistication of the specifications. These markets are then operating as "cash" markets. Although generally much smaller in volumes, they are far more numerous than one might expect. Actually, with the rising requirements from the cosmetics industry, much research is being done on many

the last few days) such as illustrated by the recent evolution of the Commodity Research Bureau Index (CRB Index - figure 22), the current fire on soybean complex (figure 23 for soybean meal) and grain prices is an important reminder that the key farm (but also food) commodities are functioning under totally different principles than the other commodities of extractive origin such as petroleum and metals. Although technically, their reference markets are operating under very similar, if not identical, systems, the fundamentals of their supply/demand balances are completely different.

The seasonality of production and the importance of the climate factor combined with the competition for arable land are the key factors under which the uncertainty of the supply/demand balance materializes. Indeed, on the demand side, the basic requirements of the human population do not change dramatically from one season to the other. As a consequence, the volatility of prices for these farm commodities is fundamentally more generated by the supply side while, for the other extractive commodities, the influence of the demand side is far more important. Of course, all this is very much the case for all vegetable oils as illustrated on figure 24. However, we know that the introduction of biodiesel (or ethanol for grains) as an alternative additional demand generates some side effects that the market has not yet fully recognized but which could become important in a near future.

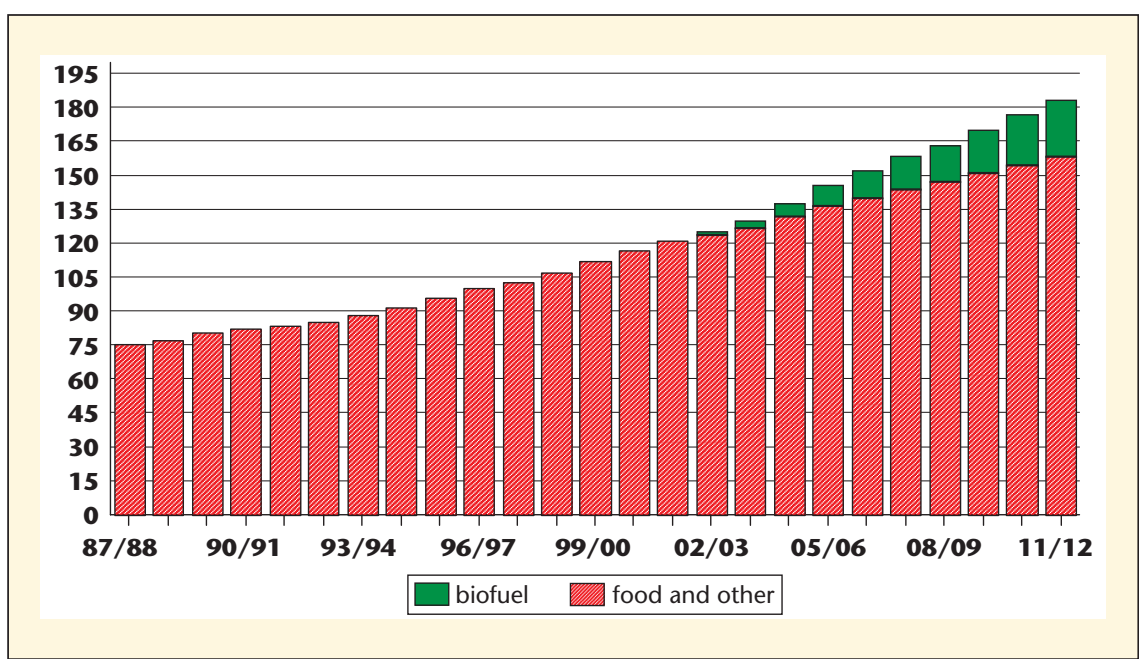

Figure 19. World consumption of 17 oils and fats (total usage in Mn T).

\section{Conclusion: How has globalization modified the picture in the oilseeds complex?}

It is fortunate to see that the markets of oilseeds, oils and meals are truly globalized because this process of opened trade channels has enabled the sector to meet the supply requirements of a quickly rising demand coming from both the population and all the industrial usages including alternative "green" energy. These developments were made at the expense of other acreage utilization, including grains but also at the expense of the wild tropical forest in both south-east Asia and South America. A continuation of the strong demand on those commodities does create significant risk for the remaining wild forest, particularly in South America. Through genetics, bio- 


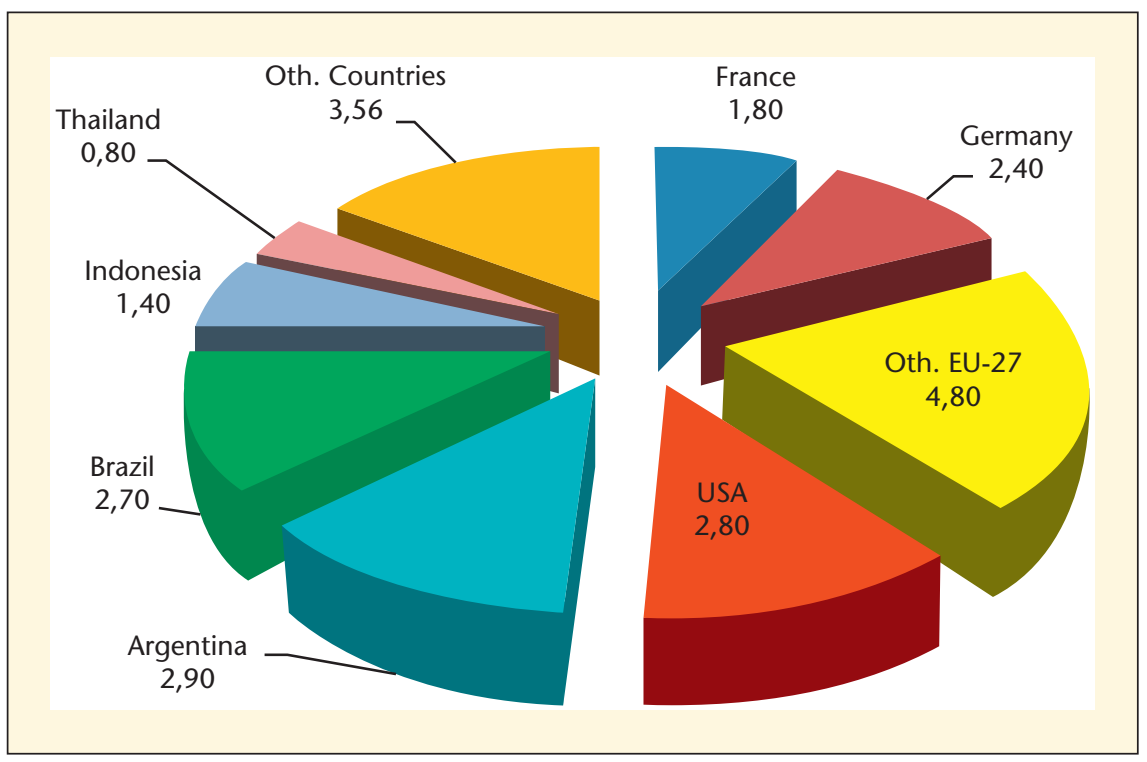

Figure 20. World production of Biodiesel in year 2012 (Forecast), in Mn T.

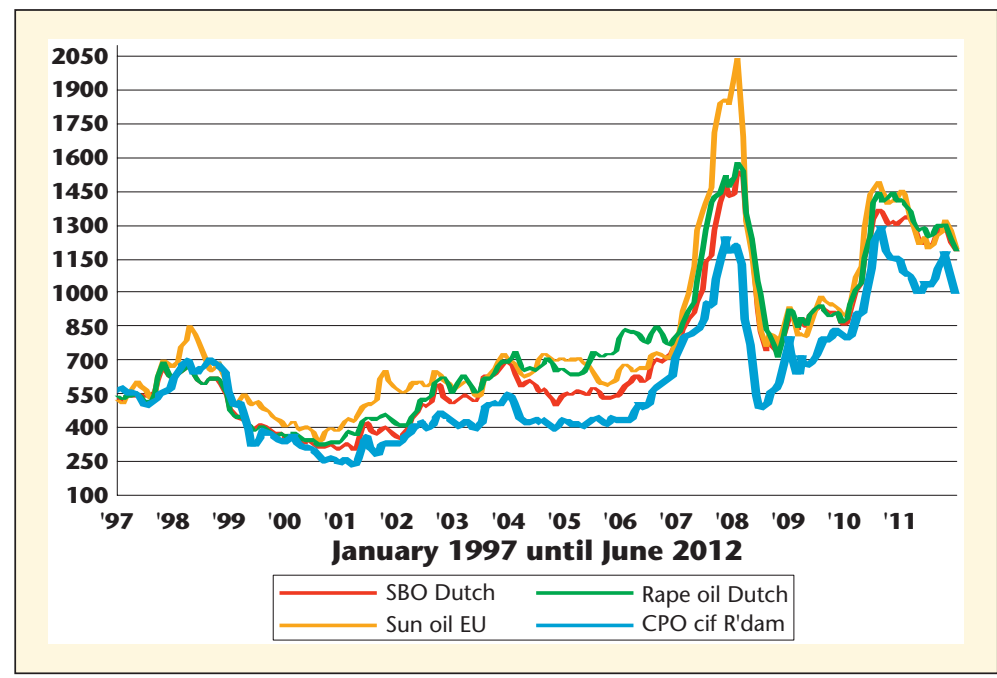

Figure 21. Monthly prices of 4 oils (in US $\$ / T$ ).

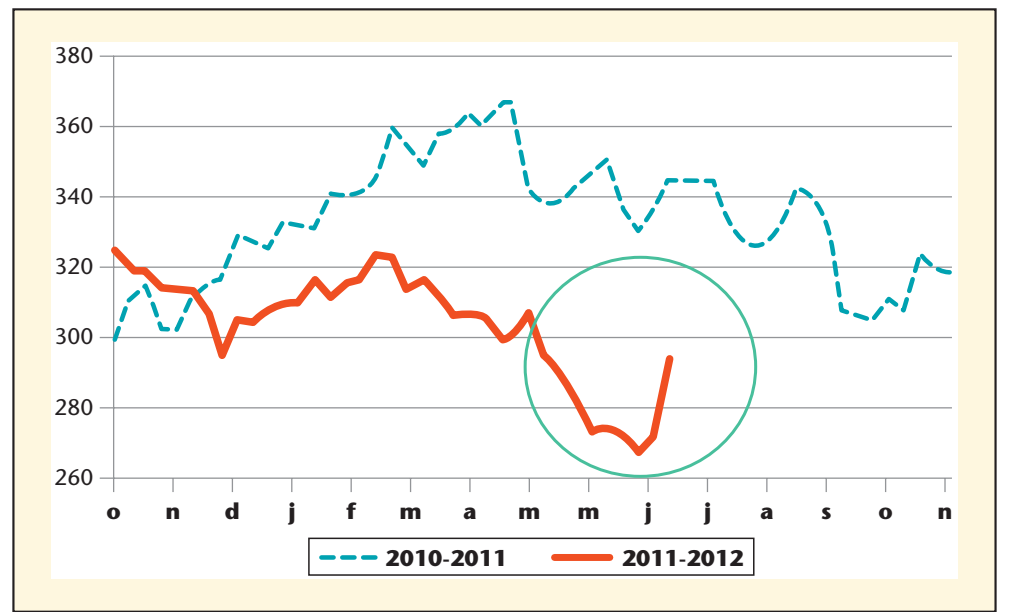

Figure 22. Commodity Research Bureau (CRB) Index in 2010-2011 and 2011-2012. 


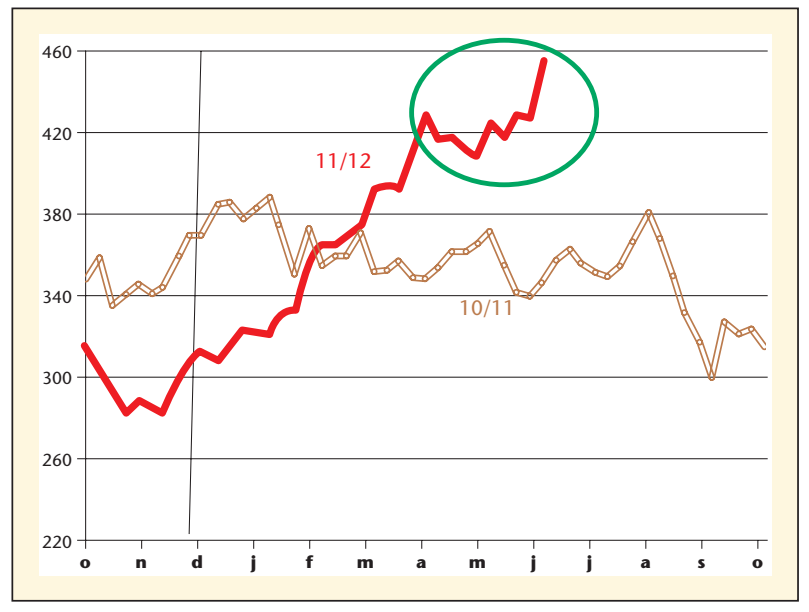

Figure 23. Soybean meal in US \$/short ton (Chicago Board of Trade, basis October-October).

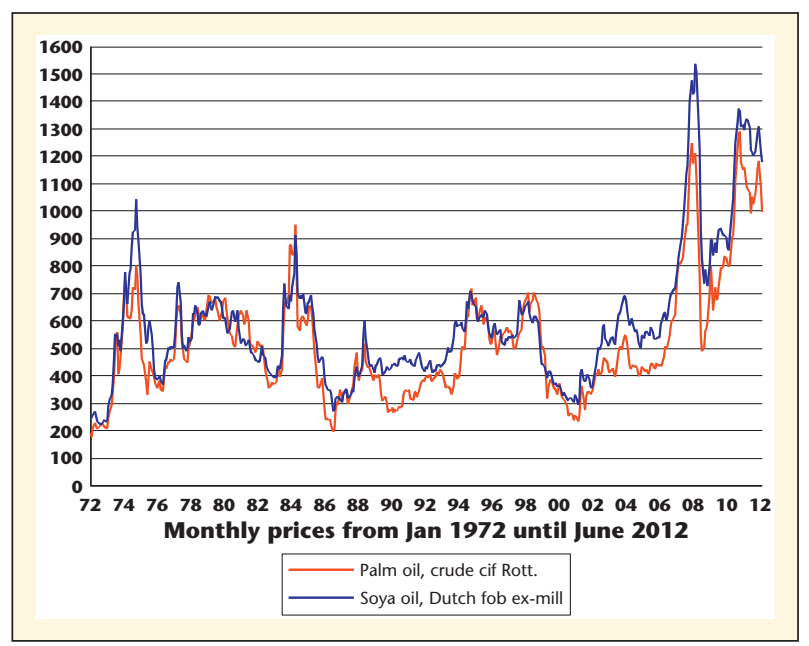

Figure 24. Monthly prices of soya oil and palm oil (US $\$ / M n T)$.

logical sciences and numerous other agricultural improvements, including the protection against diseases through the GMO seeds, agricultural yields have been rising significantly in the past decades. Whether or not we are experiencing a new "green revolution" as in the 1950's for grains, still remains to be seen although it will be a necessity in order to ensure the long-term adequate supply of this essential food staple that is required by human physiology.

However, for the time being, over the past three decades, demand growth has not been fully counter-balanced by production growth. As a consequence, unless some strict reallocation of acreage is effectively organized or new high yielding technologies are developed, it is a fact that vegetable oil will keep a strong demand base for a long time. Such demand growth will be compounded by the mechanical demand from economic growth in highly populated emerging economies. As a consequence, the balancing of supply and demand is expected to remain a tight exercise every year. Fortunately, the combination of tropical and temperate origins of vegetable oils allows a convenient "hedge" against the chances of rising climate changes. But the wide geographical dispersion of surplus regions and deficit regions will continue to require quite active balancing through international trade.

At the end of the day, the future of the entire industry largely lies in technology: technology at production level through improvement of yields and the quality of vegetable oils, through a better use of disease control; technology down the value-chain for better use of these complex products; and also recycling technology of all farm products to ensure the best usage of these high value food and feed products. Of course, the final stake is to ensure the proper feeding of a 9 billion people population in a not too far future.

Conflicts of interest: none 